EESTI NSV TEADUSTE AKADEEMIA TOIMETISED, GEOLOOGIA

ИЗВЕСТИЯ АКАДЕМИИ НАУК ЭСТОНСКОЯ ССР. ГЕОЛОГИЯ

PROCEEDINGS OF THE ACADEMY OF SCIENCES OF THE ESTONIAN SSR. GEOLOGY

$1985,34,3$

удК $622.14 ; 550.8$

С. ДЕТКОВСКИИ, В. ПЕТЕРСЕЛЛЬ, Р. ПЯЗОК

\title{
ОБ ЭКОНОМИЧЕСКОЙ ЦЕЛЕСООБРАЗНОСТИ ВКЛЮЧЕНИЯ ГЛАУКОНИТОВЫХ ПЕСЧАНИКОВ В КОНТУР ВЫЕМКИ ФОСФОРИТНЫХ ЗАЛЕЖЕИ ЭСТОНИИ ПОДЗЕМНЫМ СПОСОБОМ
}

На значительной части площади Раквереского месторождения ракушечных фосфоритов промышленный пласт перекрыт сверху слоем слабосцементированных глауконитовых песчаников мощностью $0,6-1,1$ м, который образует неустойчивую непосредственную кровлю, усложняющую из-за самообрушения разработку месторождения подземным способом. Выемка пород непосредственной кровли представляется неизбежной. Нижняя часть слоя глауконитового песчаника обогащена фос: фором и содержит до $9 \% \mathrm{P}_{2} \mathrm{O}_{5}$ при среднем содержании по слою около $2 \%$. Выше глауконита залегают крепкие доломитизированные известняки, образующие основную кровлю промышленного пласта.

Разработка промышленного пласта в принципе возможна двумя технологическими способами. При первом из них глауконит извлекают селективно как пустую породу и размещают в камерных выработках шахты. Заодно проводится крепление основной кровли штангами. После этого приступают к выемке промышленного пласта. Второй способ представляет собой валовую выемку пластов фосфорита и глауконитового песчаника с обогащением полученной горной массы. Селективная выемка исключает разубоживание руды глауконитом, но зато усложняет технологию и повышает затраты на выемку фосфорита. Почти вдвое увеличивается удельный объем нарезных работ в блоке, необходимы дополнительные затраты на извлечение глауконита. Кроме того, малая мощность пласта глауконита, недостаточная для размещения забойного оборудования, предопределяет необходимость его выемки с присечкой пород основной кровли или верхней, наиболее богатой части промышленного пласта. В последнем случае будут дополнительные потери фосфорита.

Наиболее реальной и приемлемой, с точки зрения технологии и организации горных работ, представляется валовая выемка фосфорита и глауконитового песчаника. Однако обоснование возможности и целесообразности ее применения требует предварительного изучения ряда вопросов, важнейшими из которых являются определение влияния примеси глауконита на качество добываемой руды (горной массы) и на показатели ее обогащения, установление сравнительной экономической эффективности рассматриваемых технологий. Результаты исследований этих вопросов и составляют предмет настоящей статьи. Исследования выполнялись в условиях наиболее перспективного участка Раквереского фосфоритоносного района - Кабала (подсчетный блоқ $\mathrm{C}_{2}$ - III), изученного на стадии детального поиска.

Вначале на основании данных опробования и результатов химического. анализа керновых проб были исследованы

1 ENSV TA Toimetised. G 31985 
пределения полезного компонента по мощности промышленного пласт Установлено, что от кровли к подошве содержание $\mathrm{P}_{2} \mathrm{O}_{5}$ снижается по параболической зависимости, выражающейся уравнением регрессии

$$
\alpha(h)=15,6-1,07 h-0,01 h^{2},
$$

где $\alpha(h)$ - содержание $\mathrm{P}_{2} \mathrm{O}_{5}$ в сечении пласта, $\%, h-$ расстояние от кровли пласта до отметки данного сечения, м.

График зависимости - эмпирическая (пунктир) и теоретическая (сплошная) линии регрессии - приведен на рис. 1. Установлена явная корреляционная связь между рассматриваемыми признаками. Индекс корреляции составляет 0,405 (с доверительными границами при $95 \%$-ной надежности $0,365-0,445)$, оценка тесноты связи $0,405>0,078$ свидетельствует о ее реальности.

Исходя из полученной регрессионной зависимости были рассчитаны средние содержания $\mathrm{P}_{2} \mathrm{O}_{5}$ в добываемой руде для двух возможных вариантов технологии. Мощность слоя глауконита принята $1,1 \mathrm{~m}$, среднее содержание в нем $\mathrm{P}_{2} \mathrm{O}_{5} 2 \%$. При селективной разработке выемка глауконита ведется с присечкой верхней части промышленного пласта 0,7 м, чтобы обеспечить минимально необходимую по технологическим условиям вынимаемую мощность 1,8 м (рис. 2). В случае валовой выемки промышленный пласт и глауконит извлекают как один слой вплоть до основной кровли - известняков.

При селективной технологии среднее содержание $\mathrm{P}_{2} \mathrm{O}_{5}$ в добываемой руде снижается монотонно по мере увеличения мощности промышленного пласта (рис. 2, 1). Если средняя мощность по участку 5,2 м (с учетом потерь в верхней части пласта вынимаемая мощность состав-

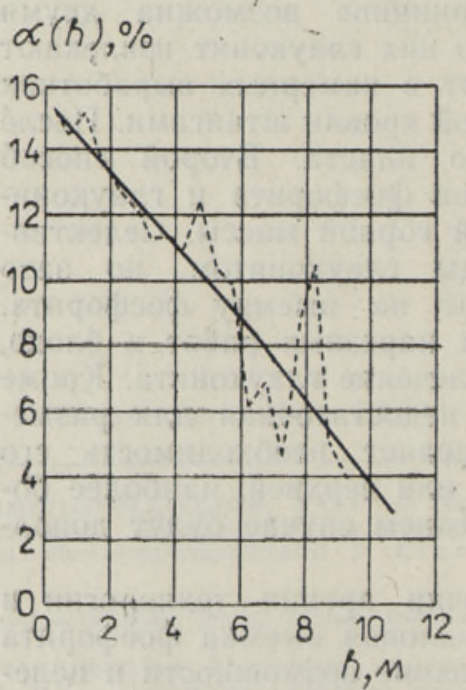

Рис. 1.

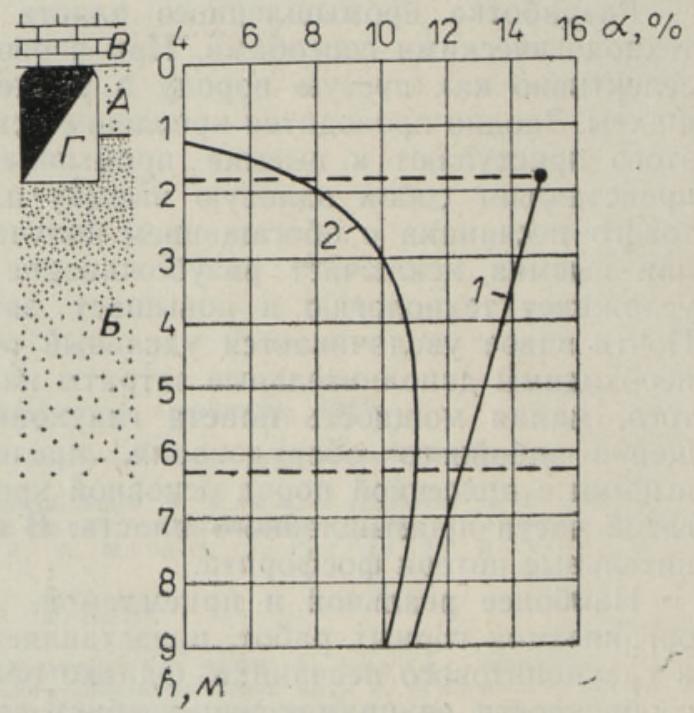

Рис. 2.

Рис. 1. Распределение содержания $\mathrm{P}_{2} \mathrm{O}_{5}$ по мощности промышленного пласта (отсчет мощности от кровли пласта).

Рис. 2. Изменение среднего содержания $\mathrm{P}_{2} \mathrm{O}_{5}$ в руде в зависимости от вынимаемой мощности пласта. 1 - селективная выемка фосфорита и глауконитового песчаннка (на схеме слева от графика: $A$ - глауконнтовый песчаник, $B$ - промышленный нласт, $B$ - основная кровля промышленного пласта, $\Gamma$ - выемка глауконитового песнаника), 2 - валовая выемка. 
яет 4,5 м), то средннеé содержание $\mathrm{P}_{2} \mathrm{O}_{5} 12,3 \%$. Прри валовой выемкеิ реднее содержание изменяется в зависимости от вынимаемой мощости по-разному (рис. 2, 2). Вначале оно повышается за счет уменьцения удельного веса примеси глауконита в добываемой руде, а затем ачинает снижаться, поскольку преобладающим становится фактор остепенного ухудшения качества в нижней части пласта. По мере оста вынимаемой мощности сокращается также разница в содеркании по сравниваемым способам технологии. Например, при мощости 5,2 м валовая выемка дает $11 \%$, т. е. всего лишь на $1,3 \%$ меньІе, чем селективная выемка. Таким образом, среднее содержание поезного компонента в руде за счет разубоживания ее глауконитом в елом по участку изменяется весьма незначительно.

Для изучения влияния примесн глаукөнита на показатели обогаимости руды нами были выполнены специальные лабораторные исслеования. Обогащение материала проводилось малыми (до $10 \mathrm{kr)} \mathrm{тех-}$ ологическими пробами из кернов буровых скважин длиной 1,5 и 2,9 м, де 0,8 и 1,1 м составляли глауконитовые песчаники, а остальные 0,7 1,8 м были представлены рудой, содержащей около $60-70 \%$ детриа створок фосфатных оболоидов. Для сравнения обогащали также удные пробы, не содержащие существенной примеси глауконита. Маериал дробили в щековой и валковой дробилках и затем измельчали о крупности 0,3 мм в шаровой мельнице. Измельченную руду обес-

Таблица 1

Минеральный состав малых технологических проб и продуктов их обогащения по данным рентгенодифрактометрического анализа

\begin{tabular}{|c|c|c|c|c|c|c|c|}
\hline \multirow{2}{*}{$\begin{array}{l}\text { Шифр } \\
\text { пробы }\end{array}$} & \multicolumn{7}{|c|}{ Содержание минералов, \% } \\
\hline & Кварц & $\begin{array}{c}\text { Каль- } \\
\text { цит }\end{array}$ & $\begin{array}{l}\text { Доло- } \\
\text { мит }\end{array}$ & $\begin{array}{c}\text { Франко- } \\
\text { лит }\end{array}$ & Пирит & $\begin{array}{l}\text { Глау- } \\
\text { конит }\end{array}$ & Прочие \\
\hline
\end{tabular}

T-13 -34

T-34

T-58*

$\mathrm{T}-60^{*}$

T-1

T- $-58^{*}$

$\mathrm{T}-60^{*}$

$\mathrm{T}-1$
$\mathrm{~T}-3$
$\mathrm{~T}-\mathrm{H}$

$\mathrm{T}-58^{2}$

T- $60^{*}$

$\mathrm{T}-1$

$\mathrm{T}-34$

$\mathrm{T}-58^{*}$

$\mathrm{T}-60^{*}$

Исходная руда

\begin{tabular}{|l|c|c|c|c|c|c}
60,28 & 1,15 & 2,76 & 35,83 & - & - & $=$ \\
86,50 & - & 2,48 & 11,02 & $\overline{7}$ & - \\
34,35 & 1,63 & 1,68 & 41,66 & 0,74 & 19,74 & $=$ \\
33,70 & - & - & 33,80 & 2,17 & 30,33 & $=$
\end{tabular}

\section{Концентрат}

\begin{tabular}{l|l|r|r|r|l|l}
8,00 & - & 4,85 & 87,15 & - & - & $=$ \\
7,41 & - & 16,64 & 75,95 & - & - & $=$ \\
5,05 & - & 4,12 & 89,43 & 1,40 & - & $=$ \\
7,48 & - & - & 89,72 & 2,80 & - & -
\end{tabular}

\section{Шламы}

\begin{tabular}{l|c|c|c|c|c|c}
43,38 & 3,23 & 7,05 & 46,35 & - & - & - \\
67,73 & - & 7,88 & 24,38 & $\overline{-}$ & $\overline{-}$ & $\overline{-}$ \\
19,14 & $\overline{-}$ & 2,08 & 39,15 & 1,64 & 30,07 & 8,47 \\
27,00 & 2,22 & - & 32,50 & 1,47 & 27,49 & 9,32
\end{tabular}

\section{Хвосты}

р н м е ч а н ие. Места отбора проб см. табл. 2.

Шифр пробы разубоженной глауконитом руды. Прочерки означают, что мннерала продукте менее $1 \%$. 
Таблица :

Химический состав малых технологических проб

и продуктов их обогащения

\begin{tabular}{|c|c|c|c|c|c|c|c|c|c|c|}
\hline \multirow{3}{*}{$\begin{array}{l}\text { Шифр } \\
\text { пробы }\end{array}$} & \multirow{3}{*}{$\begin{array}{c}\text { Выход } \\
\text { про- } \\
\text { дукта, } \\
\%\end{array}$} & \multicolumn{7}{|c|}{ Показатели обогащения, \% } & \multirow{2}{*}{\multicolumn{2}{|c|}{ Модули }} \\
\hline & & $\begin{array}{l}\text { Нераст- } \\
\text { воримый } \\
\text { остаток }\end{array}$ & \multicolumn{2}{|c|}{$\mathrm{P}_{2} \mathrm{O}_{5}$} & \multicolumn{2}{|c|}{$\mathrm{MgO}$} & \multicolumn{2}{|c|}{$\mathrm{Fe}_{2} \mathrm{O}_{3}$} & & \\
\hline & & $\begin{array}{l}\text { Содер- } \\
\text { жание }\end{array}$ & 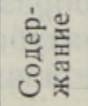 & 总 & 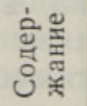 & 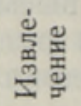 & 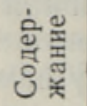 & 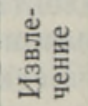 & $\mathrm{MgO}$ & $\mathrm{Fe}_{2} \mathrm{O}_{3}$ \\
\hline
\end{tabular}

\section{Исходная руда}

ПТ-13
ПТ-34
ПТ-49
ПТ-50
ПТ -52
ПТ-57
ПТ -58
ПТ -60

\begin{tabular}{l|r|}
60,28 & 12,89 \\
85,36 & 4,18 \\
47,72 & 17,14 \\
46,92 & 17,96 \\
38,88 & 21,72 \\
76,19 & 7,76 \\
48,79 & 14,27 \\
57,90 & 11,32
\end{tabular}

$\left|\begin{array}{l}0,94 \\ 0,65 \\ 0,54 \\ 0,55 \\ 0,63 \\ 0,16 \\ 1,28 \\ 0,85\end{array}\right|$

$\left|\begin{array}{l}0,93 \\ 0,98 \\ 1,84 \\ 0,94 \\ 1,04 \\ 0,55 \\ 2,88 \\ 3,34\end{array}\right|$

\begin{tabular}{|l|l}
0,072 & 0,071 \\
0,156 & 0,234 \\
0,031 & 0,107 \\
0,031 & 0,052 \\
0,029 & 0,047 \\
0,021 & 0,071 \\
0,089 & 0,202 \\
0,075 & 0,295
\end{tabular}

\section{Концентрат}

\begin{tabular}{l|r|}
$\Pi T-13$ & 28,7 \\
ПT-34 & 9,2 \\
ПT-49 & 42,3 \\
ПT-50 & 40,5 \\
ПТ-52 & 46,3 \\
ПT-57 & 15,0 \\
ПT-58 & 30,1 \\
ПТ-60 & 24,7 \\
\hline
\end{tabular}

$\begin{array}{r}4,66 \\ 7,79 \\ 10,31 \\ 8,42 \\ 6,60 \\ 5,35 \\ 4,48 \\ 7,21 \\ \hline\end{array}$

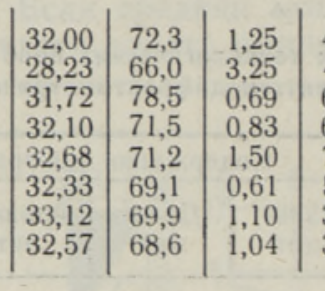

\begin{tabular}{|l|l|l|}
43,0 & 2,02 & 35,4 \\
48,4 & 1,25 & 14,5 \\
63,0 & 1,50 & 36,6 \\
68,0 & 1,75 & 53,8 \\
77,5 & 1,08 & 45,5 \\
56,3 & 0,75 & 20,0 \\
34,0 & 1,52 & 19,7 \\
37,7 & 2,71 & 27,3
\end{tabular}

\section{Шламы}

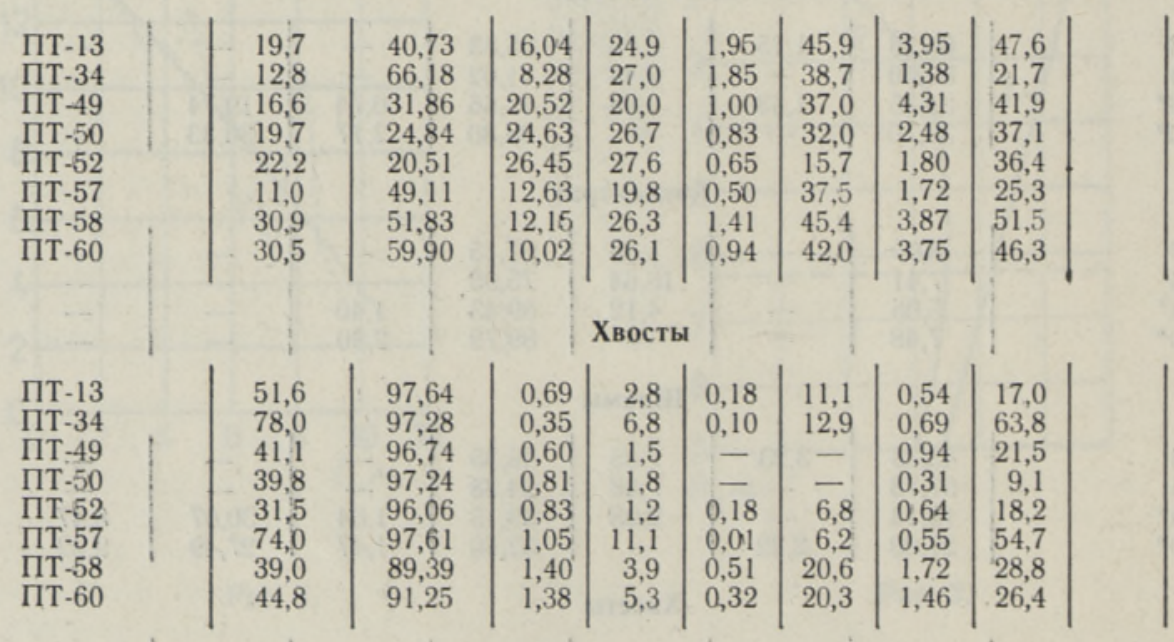

Примеяание. Места отбора малых технологических проб из фосфоритных руд участка Қабала: ПТ-13 - скв. 1550, гл. 93,9-99,9 м; ПТ-34 - скв. Р-1752, гл. 105,2106,4 м; ПТ-49 - скв. Р-1717А, гл. 80,8-87,1 м (глауконитовый песчаник - 0,5 м); ПТ-50 - скв. Р-1717А, гл. 81,3-87,1 м; ПТ-52 - скв. Р-1735, гл. 87,5-91,0 м; ПТ-57 - скв. Р-1725, гл. 91,7-96,1 м; ПТ-58 - скв. Р-1710, гл. 59,4-62,3 м (глауконитовый песчаник - 1,1 м); ПТ-60 - скв. Қ3-1-2, гл. 98,9-100,4 м (глауконитовый песчаник $-0,8$ м). 
шламливали по классу 30 мкм. Флотацию всех проб проводили по циионной схеме на машине ФМ-2M (объем камеры 0,25 л) по традирольную флотацию руды илу, предусматривающему основную и конттом водообороте с возвратом ивйную очистку концентрата при замкнуции в предшествуюшую пом промпродуктов из последующей операчестве анионного соби. Флотационными реагентами послужили: в ка- натриевое мыло сырого таллового масвителя флотации кварате - керосин, регулятора $\mathrm{pH}$ - сода, пода-

Полученные кварца - жидкое стекло.

состав технологическихтаты приведены в табл. 1 и 2. Минеральный данным рентгенодифрактомет и продуктов обогащения определен по туском государственном унетрического анализа, выполненного в Тархиминески

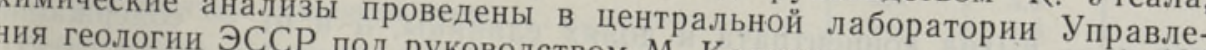
ния геологии ЭССР под руководством М. Калкун.

Исследования показали, что наличие глауконита в обогащаемой фосфоритной руде практически не оказывает влияния на качесто кон центрата. Из проб с магниевым модулем менее 0,12 получен концентрат с содержанием $31-33 \% \quad \mathrm{P}_{2} \mathrm{O}_{5}$ при извлечении его $68,6-78,5 \%$ (табл. 2). Глауконит при анионной схеме флотации ведет себя инертно. Являясь наиболее мягким минералом в обогащаемом материале, он практически полностью переходит в шламы, а зерна его крупнее 30 мкм остаются в камерном продукте - хвостах (табл. 1). Глауконита в концентрате ничтожно мало - менее $1 \%$. За счет примеси клауконита в руде значительно увеличивается выход шламов и нескольдля условий обогащению с мокарного эксперимента. Переход к промышленному может дать уменьшен стадийным дроблением и измельчением руды этого повысится извлеч выхода шламов примерно вдвое, в результате тери. Таким образом, есть в $\mathrm{P}_{2} \mathrm{O}_{5}$ в концентрат и уменьшатся его понита в обогаш не изменяет ни технологическе лишь на затраты по обогащению, но получаемого концентрата

нс. 3. Зависимость извлечеия $\mathrm{P}_{2} \mathrm{O}_{5}$ в концентрат от реднего содержания его в богащаемой руде. Точки 1 и - пробы с содержаннем в руде глауконита.

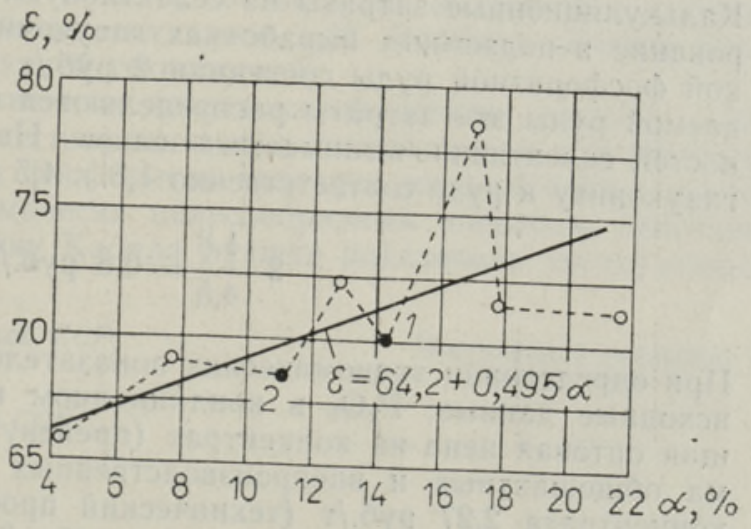

Затраты по обогащению на единицу концентрата при заданной техологии процесса зависят в основном от двух параметров: содержаия полезного компонента в обогащаемой руде и извлечения компоалич в концентрат. Обработка данных табл. 2 позволила установить личие линейной взачмосвязи (рис. 3) между извлечением $\mathrm{P}_{2} \mathrm{O}_{5}(\varepsilon)$ 
и содержанием его в поступающей на обогащение руде $(\alpha)$. Эту взаимосвязь можно выразить уравнением регрессии (при коэффициенте корреляции 0,633)

$$
\varepsilon=64,2+0,495 \alpha,
$$

откуда видно, что с увеличением $\mathrm{P}_{2} \mathrm{O}_{5}$ на $1 \%$ извлечение повышается примерно на $0,5 \%$.

Товарный выход концентрата в зависимости от содержания $\mathrm{P}_{2} \mathrm{O}_{5}$ в руде и концентрате определяется как

$$
\varphi=\frac{\alpha \cdot \varepsilon}{100 \alpha_{k}}=\frac{64,2 \alpha+0,495 \alpha^{2}}{100 \alpha_{k}}
$$

где $\varphi$ - выход концентрата в долях единицы, $\alpha$ и $\alpha_{k}-$ содержание $\mathrm{P}_{2} \mathrm{O}_{5}$ соответственно в руде и концентрате, \%.

Экономические показатели двух рассматриваемых способов техно логии мы определяли с помощью разработанных в Институте эконо мики АН ЭССР экономико-математических моделей затрат на эксплуа тацию фосфоритных месторождений системой с монолитной закладко выработанного пространства. При определении экономических показа телей учитывали различные по сравниваемым способам средние содер жания полезного компонента в добываемой руде и уровни извлечени запасов месторождения.

Себестоимость добычи руды рассчитывали в зависимости от выни маемой мощности $(h)$ по формуле

$$
C_{p}=2,12+\frac{162 h^{2}+3101 h-178}{361 h^{2}+69 h}, \text { руб./т. }
$$

Себестоимость обогащения в расчете на концентрат определяли зависимости от его товарного выхода $(\varphi)$ как

$$
C_{\text {об. }}=\frac{1,78}{\varphi}+1,51, \text { руб./т. }
$$

Калькуляционные затраты на селективную выемку, доставку и склад рование в подземных выработках глауконитового песчаника с присе кой фосфоритной руды составили 2 руб./т $\left(4,5\right.$ руб./ $\left.{ }^{3}\right)$. На 1 т доб ваемой руды эти затраты распределяются с учетом соотношения мо ностей селективно вынимаемых слоев. Например, при мощности глаукониту и руде соответственно 1,8 и 4,5 м величины затрат состав

$$
2 \cdot \frac{1,8}{4,5}=0,8 \text { руб./т. }
$$

При определении экономических показателей были приняты следуюш исходные данные: $\mathrm{P}_{2} \mathrm{O}_{5}$ в кондиционном концентрате $28 \%$, действу щая оптовая цена на концентрат (прейскурант 1982 г.) 43 руб./т, с ма общешахтных и внепроизводственных расходов в себестоимо концентрата 2,27 руб./т (технический проект рудника Тоолсе). По ченные результаты расчетов даны в табл. 3 .

Из сравнения экономических показателей видно, что при вало выемке промышленного пласта с глауконитовым песчаником себест мость добычи руды (горной массы) на 25\% ниже, чем при селектив выемке. Однако за счет ухудшения качества добываемого сырья растают затраты на его обогащение. В общей же сложности эконо на горных работах перекрывает дополнительные затраты по обога 
MAJANDUSLIKUST OTSTARBEKUSEST ALLMAAKAEVANDAMISEL EESTIS On uuritud võimalusi kaevandada fosforiiti koos kihi vähepüsivaks vahetuks laeks. glaukoniitliivakiviga, mis on fosfori keskmise kvaliteedi muutumist ja tehtud glaukoniiOn vaadeldud kaevandatavi laboratoorsed rikastuskatsed. Selgus, et glaukoniidi kvaliteeti. diga segunenud fosforimise tehnoloogilisi näitajaid ega saadava kontsenträajaid fosforiidi mine ei mõjuta rikastamiöe tehnoloogiliste variantide majanduslikke nät tagab maardla

On vôrreldud mäetööde tehnoloogil väljamisel. Koosväljamise variant tagab masuarlikud ja glaukoniidi koos- ning väitajad.

S. DETKOVSKY, V. PETERSELL, R. PÄSOK

\section{ON THE ECONOMIC EFFICIENCY OF INCLUDING GLAUCONITE SANDSTONE IN THE UNDERGROUND MINING}

The authors discuss the possibility of mining phosphorite ore together with the overlyin

The authors discuss the possibility of mining phosphore a soft and unstable roof of ore body
strata of glauconite sandstone which forms there a
Changes were observed in the average quality of the ore mined. Laboratory exper ments were carried out, aimed at enriching or does not affect the technological parameter ascertained that the admality of the concentrate obtained.

of enrichment or the qualitentrate of total and selective mining technologies we

more efficient, ensuring a higher extraction compared. Total mining proved to be more efficiant, 